\title{
La etnohistoria de los eventos y de los eventos nulos*
}

\author{
Raymond D. Fogelson
}

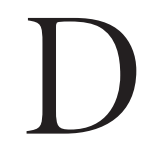
ESDE UNA perspectiva tradicional, los eventos han sido considerados como los elementos primarios en el estudio de la historia. En su calidad de unidades mínimas en el discurso histórico, los eventos deben ser descritos, analizados, ordenados, e interpretados. Herbert Butterfield (1981) y otros han demostrado que el registro de eventos es fundamental para la historia de la historia. Frecuentemente se hace una distinción entre eventos naturales e históricos. Ambos tienen que ver con el azar — un encuentro o accidente únicoaunque, mientras que los eventos naturales pueden influir o determinar los eventos históricos, éstos deben ser considerados principalmente como hechos culturales. El filósofo francés Raymond Aron arguye con precisión que "el hombre tiene una historia porque llega a ser a través del tiempo, porque construye obras que le sobreviven, porque erige monumentos al pasado" (citado en Ricoeur 1980: 3). La recuperación, reconstrucción y revivificación del pasado requiere una conciencia particular. Sin embargo, he aquí la cuestión a abordar, desde un punto de vista empírico y epistemológico: ¿Qué es un evento?, y viceversa, ¿qué es un evento nulo?

RAYMOND D. Fogelson: Universidad de Pennsylvania.

* Copyright 1988, American Society for Etnohistory. La presente traducción del manuscrito original al español fue autorizada directamente por el profesor Fogelson y realizada por David Tavárez.
Los eventos son elementos cruciales para los fundamentos de la física moderna. En términos muy simples, puede definirse un evento como aquello que ocurre en un tiempo y lugar dados, ignorando por el momento las incertidumbres de Heisenberg. Se considera también que los eventos tienen propiedades y relaciones propias. Con el desarrollo de la física de la relatividad, la noción del evento asumió un significado fundamental; para Bertrand Russell, los eventos reemplazarían nociones más vagas del cuerpo y de la sustancia, mientras que Alfred North Whitehead argumentó que los eventos se componían de los nexos de ocasiones concretas. Estas concepciones poseen la idea implícita de que los eventos se componen de procesos, cambios, sucedidos, actos, transformaciones, y otras características que son esencialmente diferentes de objetos físicos y cosas concretas. Existe también la posición más especulativa de que los objetos podrían ser simplemente un agrupamiento de eventos asociados, con la consecuencia de que los eventos serían el único objeto de nuestra ontología.

El debate filosófico sobre la posibilidad teórica de admitir la existencia de eventos nulos es relevante a esta discusión. ¿Los eventos nulos no poseen alguna propiedad física o de otra naturaleza? ¿Carecen tal vez de propiedades físicas, pero contienen ciertas propiedades necesarias para el cálculo de eventos? O, en términos positivos, ¿se pueden asignar ciertas magnitudes físicas a los eventos 


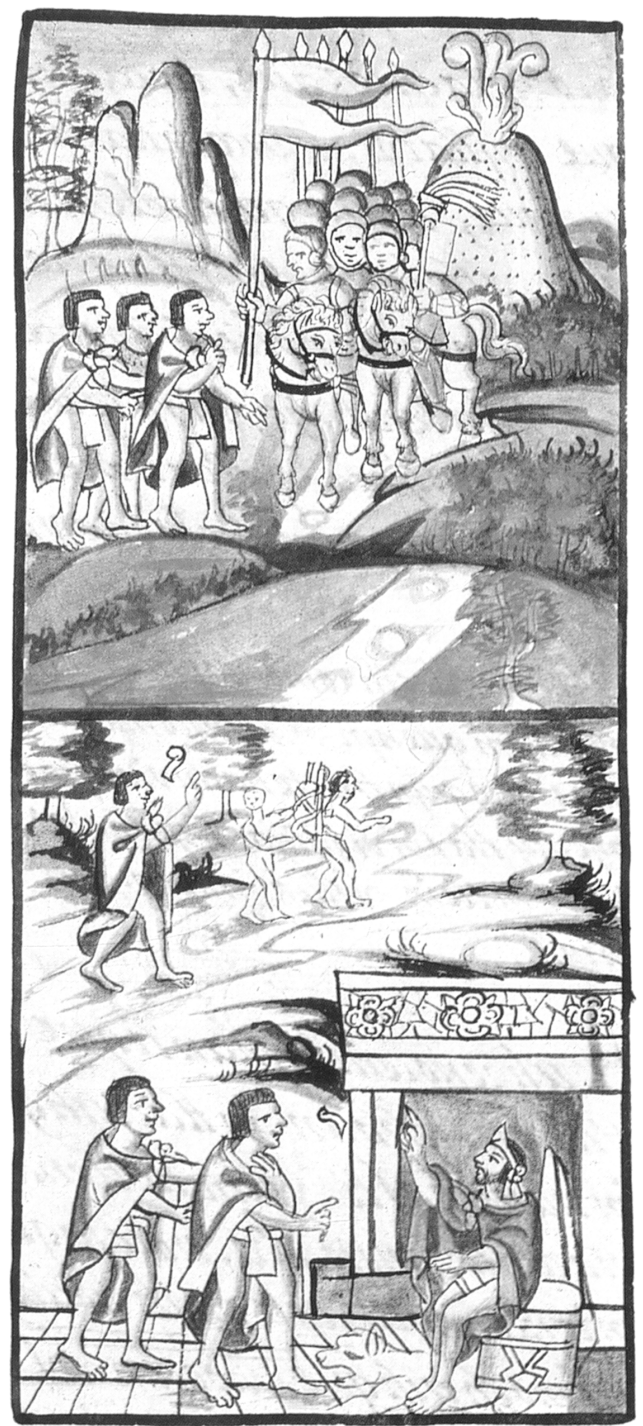

Códice Florentino

nulos? De acuerdo con el cuestionamiento de R. M. Martin (1978: 95), "si un objeto es una entidad tan fantasmal, se puede preguntar por qué admitir un [evento nulo] sería mucho peor que admitir la existencia de una clase, grupo, o relación nula".

La forma particular de la conciencia histórica occidental normalmente presume la existencia de documentos escritos, y esta presunción plantea dilemas epistemológicos particulares para los etnohistoriadores. ¿Cómo se puede dar cuenta de la historia de los llamados "pueblos sin historia", aquellos que carecen de las bibliotecas y archivos documentales acostumbrados? ¿Habría que descartarlos como pueblos que carecen de una conciencia histórica? De acuerdo con mi humilde interpretación, todos los pueblos tienen una noción del pasado, sin importar lo extraño o excepcional que dicho pasado parezca desde nuestra perspectiva condicionada por la escritura. Nuestra comprensión de la historia no occidental requiere no sólo de la producción de documentos y de una amplia concepción de lo que es un documento, sino también, un esfuerzo resoluto de tratar de comprender formas no propias del discurso y de la conciencia histórica. Fue en este sentido que yo alguna vez sugerí, con cierta exasperación, la necesidad de alcanzar lo que quise llamar un planteamiento etno-etnohistórico (Fogelson, 1974). Tal planteamiento insiste en tomar en serio las teorías autóctonas de la historia inscritas dentro de la cosmología, la narrativa, los ritos y ceremonias, y de manera más general en la filosofía y perspectiva indígenas. Aquí va implícita la presunción de que los eventos pueden ser reconocidos, definidos, evaluados y relacionados con un significado de manera distinta en tradiciones culturales diversas.

Los estudiosos franceses en torno a l'ecole des Annales han cuestionado con severidad la importancia de los eventos para la historiografía. Esta revolución en el pensamiento histórico fue iniciada en 1929 por Lucien Febvre y Marc Bloch en oposición a la llamada historia positivista. ${ }^{1}$ Esta historia no debe ser confundida con el positivismo lógico o con la filosofía positivista decimonónica de Auguste Comte, puesto que Comte de hecho anticipó muchas de las creencias de la escuela de los Annales. Teggart (1941: 108) resume de una manera sucinta la posición de Comte:

\footnotetext{
${ }^{1}$ Febvre y Bloch fundaron la influyente publicación Annales d'Histoire Économique et Sociale, pero el énfasis de Henri Berr (1900) en la historia sintética y los argumentos de François Simiand (1903) sobre datos históricos repetibles y cuantificables se anticiparon a algunos aspectos principales del planteamiento metodológico de los Annales (Wallerstein, 1979: 70). Para los annalistes, la "historia positiva" se asociaba a la historia oficialista, que enfatizaba una forma narrativa e ideográfica y que se podría designar como l'histoire historisante o l'histoire événementielle (ibid.)
} 
Para ser científica, la historia debe ser abstracta; para pasar de lo concreto a lo abstracto, debe ser liberada de toda circunstancia particular, e idealmente incluso de los nombres de hombres y pueblos. De acuerdo con Comte, los "eventos" que enfatiza la historia académica deben ser considerados "esencialmente insignificantes", equiparables a "monstruosidades" biológicas.

Creo discernir en el tipo de historia positivista que Comte y la escuela de los Annales atacaran con tanto vigor ciertas incómodas similitudes con los supuestos explícitos e implícitos de la etnohistoria que se practica en Norteamérica. Paul Ricoeur (1980: 8) ha singularizado cinco características principales de la llamada historia positivista: 1) Una actitud de objetividad neutra, comparable a la del físico que actúa independientemente del fenómeno bajo estudio; 2) un enfoque reducido a la recolección y análisis crítico de documentos (incluyendo cuestiones como su manufactura, origen, fecha, o validez); 3) la presunción de que los hechos históricos existen dentro de los documentos, y que sólo deben ser extraídos o excavados (esta idea es equiparable a la actitud de un escultor iroqués que vislumbra un falso rostro ya prefigurado en un trozo de madera de tilo o en un árbol viviente); 4) sus explicaciones consisten en la correlación entre eventos o "accidentes" particulares a lo largo de una línea temporal impuesta por los documentos; y 5) se considera al individuo como el locus esencial y el transmisor de los cambios históricos. Al presentar la crítica de los annalistes y su deconstrucción —o, mejor dicho, su descuartizamiento— de los anteriores supuestos básicos, sugeriré algunas implicaciones para la etnohistoria.

Una historia empírica, objetiva y libre de evaluaciones - lo que Peter Novick llamara Ese noble sueño [ That Noble Dream, 1988] en su reciente retrospectiva crítica de la

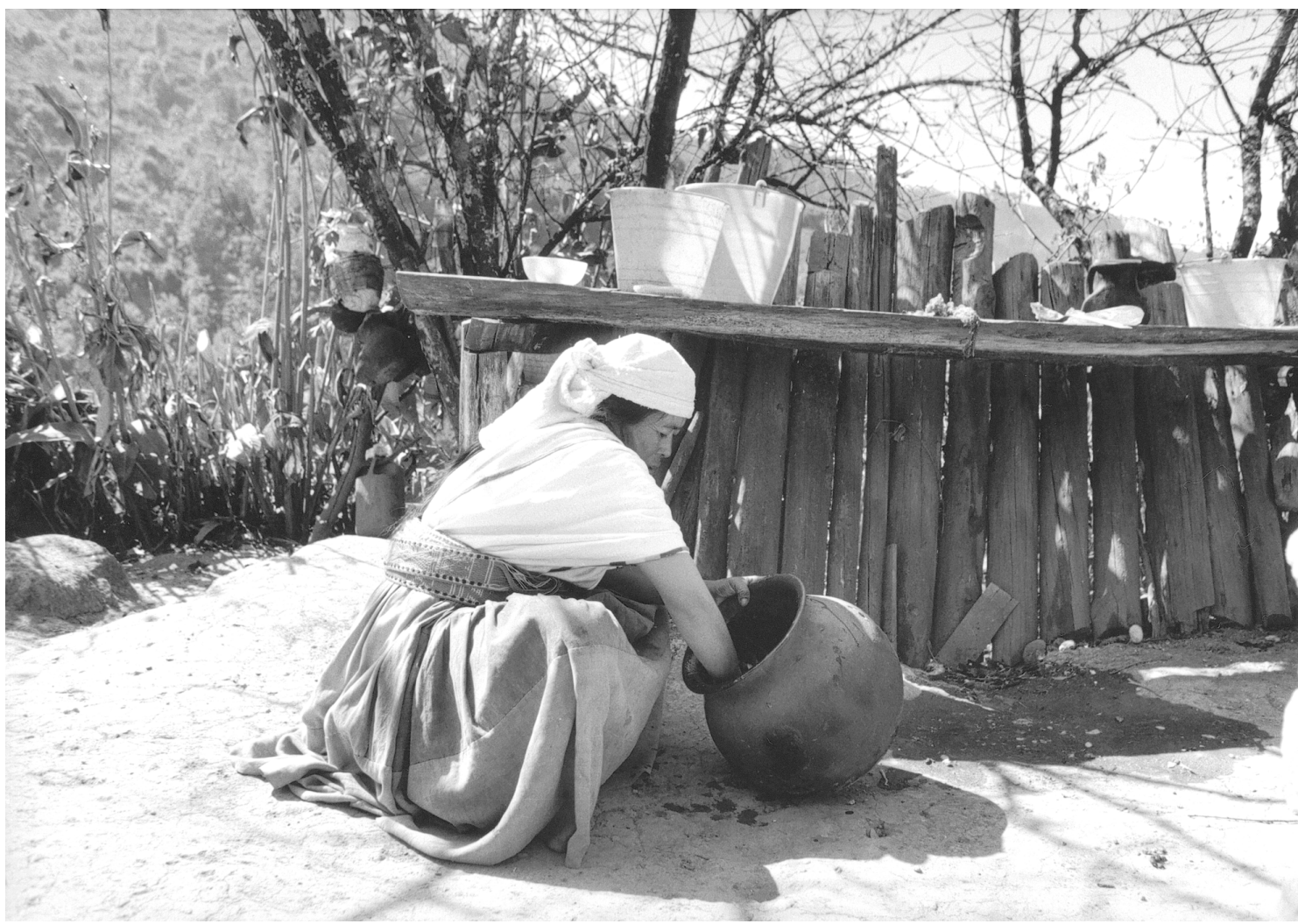

Espiritu Santo, Tamazulapan, mixe, Vittorio D’Onofri, 1995 
profesión del historiador norteamericano- puede ser para algunos un objetivo ideal en la investigación histórica, pero es un ideal imposible de realizar simplemente porque los historiadores nunca se liberan de la historia; hay una interacción continua entre pasado y presente. Los estudiosos pertenecientes a la tradición de los Annales no niegan la relevancia de eventos actuales como claves para el descubrimiento de conexiones anteriormente insospechadas en la investigación histórica (Ricoeur, 1980: 9).

Esta afirmación del valor del presente para nuestra comprensión del pasado nos hace confrontar directamente los problemas epistemológicos y metodológicos relacionados con la eterna oposición entre "presentismo" e "historicismo". Los peligros del presentismo en cuanto a la distorsión y falsificación del pasado son bien conocidos, al menos desde la explicación ofrecida por Butterfield sobre La interpretación whig de la historia [The Wig Interpretation of History, (1976 [1931])]. No obstante, algunos historiadores y autores de libros de texto norteamericanos con buenas intenciones siguen a la búsqueda de un pasado utilizable y relevante. El historicismo, la antítesis del presentismo, intenta contextualizar el conocimiento histórico para permitir la debida interpretación de eventos en el pasado. El historicismo deliberadamente guarda su distancia de los fenómenos en vías de investigación, mas también sufre la ausencia de una adecuada teoría del contexto, tanto para colocar eventos en un escenario particular, como con el fin de establecer un marco adecuado para comparar contextos distintos. Muy frecuentemente se considera que el contexto constituye una explicación, si bien el contexto es en sí mismo problemático, debiendo ser elucidado. Recurrir al determinismo contextual de manera exclusiva presenta las mismas deficiencias lógicas que el uso de un exagerado determinismo del medio ambiente. Cada evento y era histórica involucra un pasado tal que la historia podría ser leída como una serie de presentismos del pasado en contigüidad.

El reconocimiento de esta relación entre pasado y presente posee corolarios teóricos y prácticos para los etnohistoriadores. Por ejemplo, si uno está interesado en la cultura política indígena del siglo XVIII, se pueden recolectar ciertas inferencias mediante la observación de procesos políticos informales que aún ocurren en muchas reservaciones norteamericanas. A pesar de la pérdida parcial de ciertos recuerdos y de las inevitables reinvenciones, los comentarios orales sobre eventos en el pasado podrían contribuir a la interpretación de materiales manuscritos.

Aun ciertos eventos en nuestra cultura contemporánea pueden despertar la imaginación etnohistórica. Por ejemplo, algunos libros recientes sobre el caso de Patty Hearst, ${ }^{2}$ que incluyen su propia versión de los hechos, han sido publicados recientemente; es muy probable que ahí se encuentre una abundancia de materiales para estimular nuevas interpretaciones sobre las narrativas escritas por los cautivos de indígenas norteamericanos. Mirando al norte [Facing West, 1980], la mal ponderada obra de Robert Drinnon, concibe las terribles peripecias norteamericanas en Vietnam como el eslabón más reciente en una cadena continua que se extiende hasta la invasión europea inicial de América. Asimismo, la reciente conquista norteamericana de Grenada nos invita a releer bajo una luz distinta la obra teatral épica de John Dryden de 1672, La conquista de Granada por los españoles:

No hay ningún otro hombre que odie más el vivir; ¿Tendríais pues el derecho de hacerme morir? Si bien vuestros súbditos os han de obedecer Rey de mí mismo soy solo yo, sabed.

Libre soy, cual nos hizo la naturaleza, antes que Servidumbre venciera a Grandeza cuando el noble salvaje corría aún en la maleza. ${ }^{3}$

Dudo que este poema haya sido parte de las lecturas obligatorias del Pentágono o del Departamento de Estado. De cualquier manera, el primer ejemplo de la utilización del término "noble salvaje" en las letras inglesas

\footnotetext{
${ }^{2}$ N. del T.: Esta es una referencia al secuestro de Patty Hearst, la hija de uno de los dueños del conglomerado periodístico Hearst, quien, luego de haber sido capturada por el Ejército Simbiónico de Liberación, decidió unirse a este movimiento armado radical mediante el asalto a bancos y la participación en la guerrilla urbana de principios de los setenta en California.

3 Traducción del texto original: "No man has more contempt, than I, of breath / But whence hast thou the right to give me death? / Obey'd as Sovereign by thy subjects be / But now, that I alone am King of me. / I am free as Nature first made man / 'Ere the base Laws of Servitude began / When wild in the woods the noble Savage ran."
} 


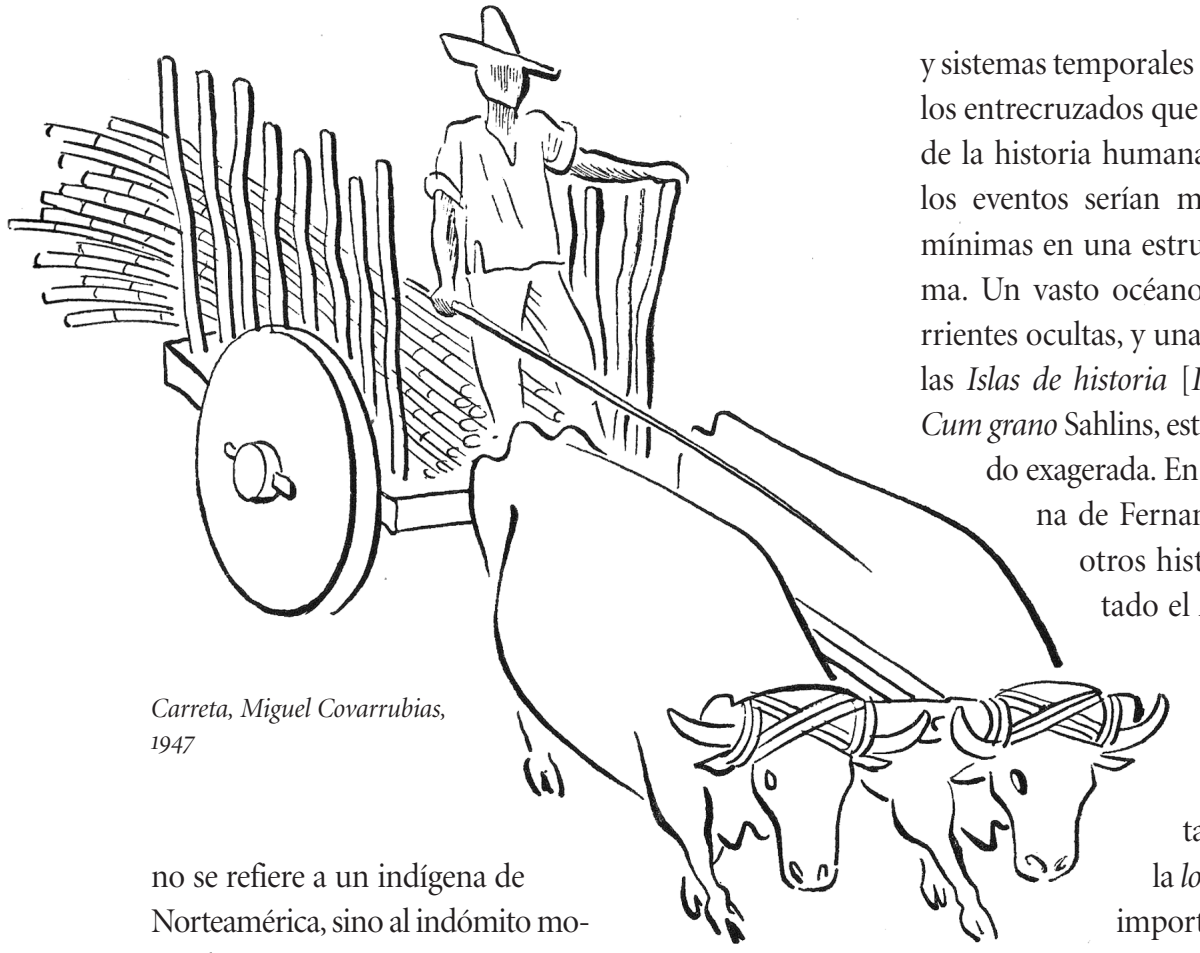
ro Almanzor. evento. Bajo las fluctuaciones de breve duración marcadas por eventos existiría una historia de lentos ritmos que se extienden a través de largos períodos. ${ }^{4}$ Me parece vislumbrar en las concepciones de Braudel una analogía implícita con la historia de la geología. Antes de que la teoría evolutiva darwinista pudiera emerger, una vasta visión temporal se hacía necesaria. Las antiguas teorías geológicas sobre el catastrofismo tuvieron que ser reemplazadas por la teoría uniformitaria del geólogo inglés Charles Lyell, quien proponía una lectura de la historia terrestre a través de procesos lentos, naturales e inexorables que operan durante períodos temporales inmensos, continuando hasta el presente.

Al minimizar su énfasis en los eventos, los annalistes también se apartan de la noción del individuo como agente histórico primario a través de una asimilación

\footnotetext{
${ }^{4}$ En su ensayo intitulado "La historia y las ciencias sociales" (1972 [1958]), Braudel bosqueja las temporalidades múltiples que utilizó en su magistral obra El Mediterráneo y el mundo mediterráneo en la era de Felipe II (1972-1973 [1949]): tiempo estructural (o longue durée), conjoncture y evento. Según Braudel, los eventos de breve duración poseen una importancia analítica menor a la de los eventos de mayor duración.
} 
parcial del pensamiento sociológico de Durkheim y Mauss, el que subraya la realidad concreta de las estructuras sociales, así como el poder evocativo de representaciones colectivas que alcanzan su forma más potente al ser consideradas como hechos sociales totales. El distanciamiento de los eventos conduce a descartar una "historia compuesta de batallas"; a su vez, la negación del individuo constituye una retirada de una historia política en la que figuran prominentemente las decisiones de líderes políticos individuales (Ricoeur, 1980: 10). La atención del investigador se dirige a ciertos grupos — a ciertas categorías o clases sociales - o a ciertas regiones, siguiendo un planteamiento que podría ser caracterizado como historia social despersonalizada.

Los trabajos sustanciales de los estudiosos pertenecientes a la escuela de los Annales se han concentrado en la historia de Europa, mas sus ideas han influenciado algunas conceptualizaciones recientes de la antropología histórica y de la antropología de la historia, particularmente aquellas propuestas por Marshall Sahlins $(1981,1985)$. El área que interesa a Sahlins es Polinesia; esta región posee una rica documentación sobre sus primeros contactos con Europa, la que Sahlins domina con maestría. Por otra parte, Sahlins es asimismo un etnólogo talentoso que posee un fino sentido del detalle, y su línea de investigación se ha involucrado de manera creciente con las nociones indígenas sobre la historia. La fusión de estos dos planteamientos ha producido algunas narrativas históricas específicamente polinesias en las que las dualidades heurísticas de Occidente - estructura $v s$. evento, infraestructura vs. superestructura, presentismo e historicismo, individuo y grupo, patrón y proceso, y Occidente $v$ s. el resto del mundo- han sido derribadas. De acuerdo con Sahlins, tanto los eventos históricos como los míticos son "reales" para los polinesios; sus tradiciones narrativas presentan una rica variedad de dioses, gobernantes y héroes individuales, y poseen una validez, lógica y dinámica interna propias que han sido constituidas culturalmente. La antropología de la historia propuesta por Sahlins constituye un planteamiento relativista y pluralista en la que la historia occidental es vista como uno de muchos productos culturales, sin vínculos privilegiados con verdades universales. No quisiera ofrecer aquí una crítica de la obra de Sahlins, puesto que la reacción crítica sin duda iniciará cuando las mandíbulas del discurso académico comiencen su lento proceso digestivo. Lo que me concierne ahora de manera particular es la posibilidad de aplicar el planteamiento de los Annales y las tendencias recientes en la antropología histórica a la reformulación de una etnohistoria de los indios de Norteamérica.

La convergencia en torno a ciertos temas parece ser evidente. El interés de los historiadores europeos en la geohistoria, el medio ambiente y el clima encuentra un paralelo en el incipiente interés de los etnohistoriadores por los factores ecológicos y geográficos que influenciaron el curso de la historia del Nuevo Mundo antes y después del contacto con Europa. Una serie de fenómenos - la sociología de la agricultura, los períodos hipertérmicos e hipotérmicos, los incendios forestales y las inundaciones, las erupciones volcánicas y los terremotos, o

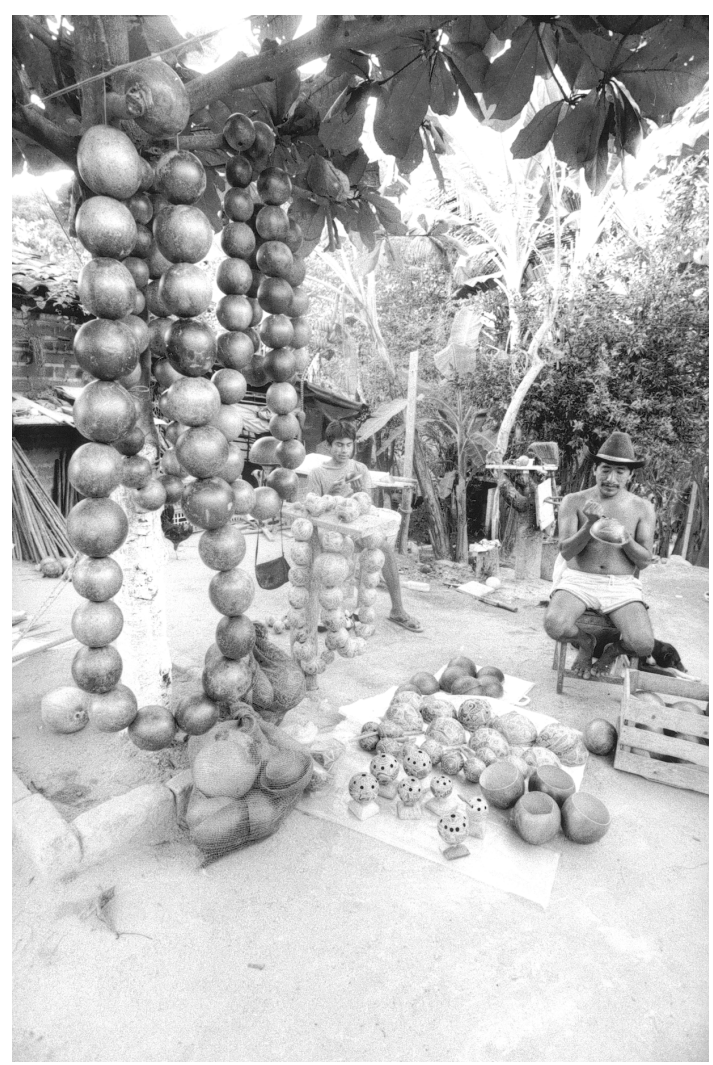

Pinotepa de Don Luis, mixteca de la Costa, Vittorio D’Onofri, 1995 


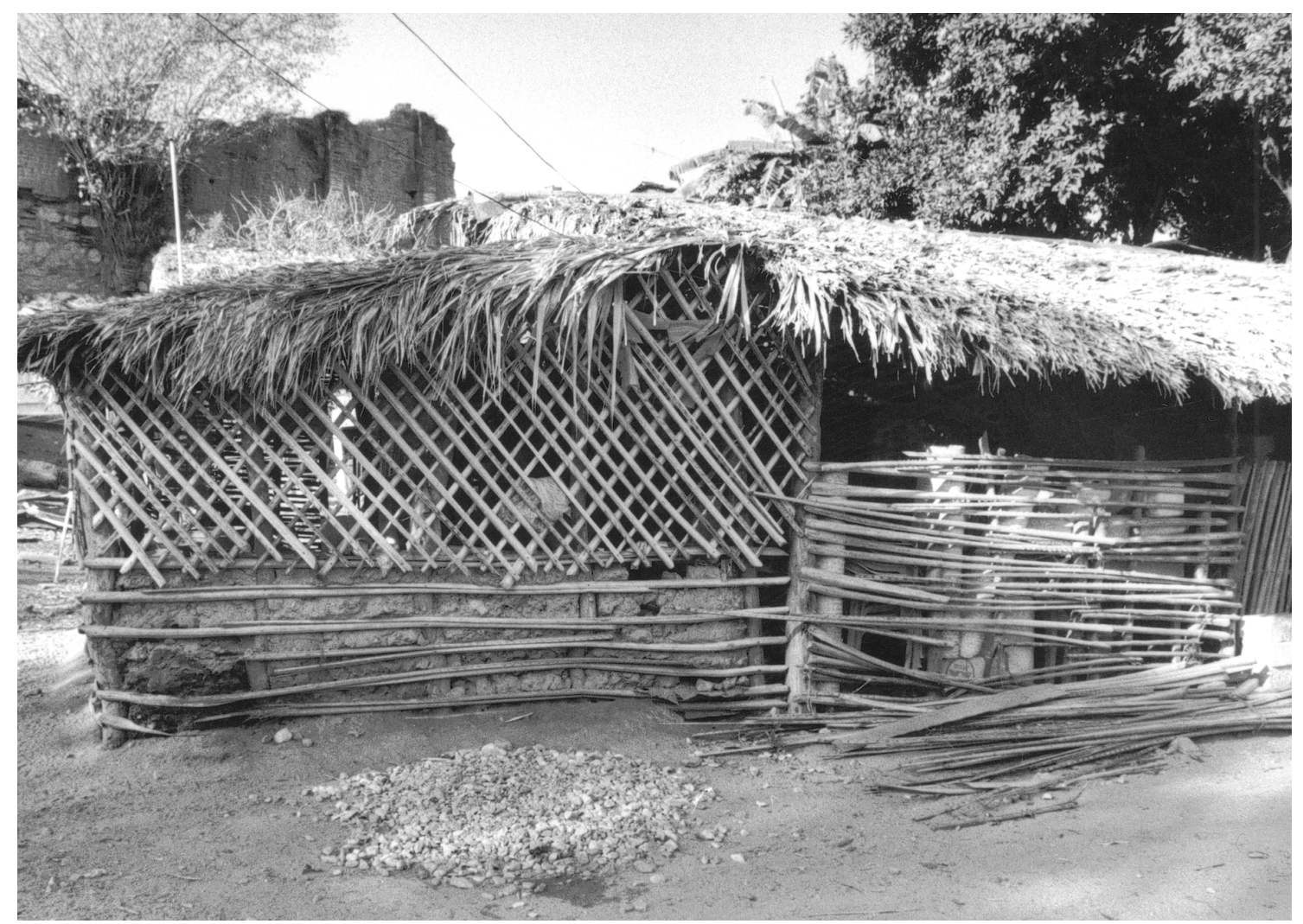

Collantes, afromixteca de la Costa, Vittorio D’Onofri, 1995

las fluctuaciones en las poblaciones de animales de caza, mosquitos o conejos - han sido caracterizados como factores influyentes en este tipo de historia. Esta perspectiva deshumanizada ha sido levemente modificada por algunos esfuerzos etnoecológicos o etnogeográficos en torno a la consideración de los significados culturales atribuidos a estos fenómenos de la naturaleza.

Otro paralelo aparente con los proyectos de los historiadores europeos es el vigoroso interés de los americanistas en la demografía, las epidemias, y los índices de mortalidad, particularmente - pero no exclusivamente- en períodos posteriores a la introducción de los patógenos europeos. Obviamente, la drástica disminución de la población indígena fue un factor decisivo en el curso de la historia indígena norteamericana, y tuvo un efecto dramático en la organización social, la conversión al cristianismo, los movimientos de revitalización, la pre- servación de tradiciones, y en muchos otros aspectos. Sin embargo, en períodos posteriores a las grandes pérdidas demográficas, se encuentran muy pocas narrativas sobre las reacciones y las racionalizaciones cognitivas de los indígenas a esta catastrófica mortalidad.

De cierta manera, la historia cultural del Nuevo Mundo se presta a algunas ideas inherentes a la longue durée, y de otra manera exhibe ciertas dificultades. El registro arqueológico revela la existencia de procesos de larga duración, y la abundante documentación colonial puede ser analizada para dilucidar tendencias, ciclos y patrones de larga duración. En Norteamérica, las altamente especializadas y poco conocidas culturas paleoindias y la monótona uniformidad de las adaptaciones de las culturas arcaicas y del desierto dan lugar eventualmente a una especialización regional creciente durante el período Woodland, acelerando la marcha hacia las grandes diferencias 
en escala y volatilidad exhibidas por ciertas regiones al inicio de los períodos Mississipian y proto-Pueblo. Aunque las diferencias en términos de complejidad cultural revelan adaptaciones ecológicas y situaciones muy distintas, dicha diferenciación cultural se redujo por medio de la rápida difusión de mercancías, tecnología e ideas a través de redes de comunicación bien establecidas. A pesar de la prematura desacreditación y abandono de los trabajos sobre la aculturación, éstos nos permiten discernir ciertas regularidades generales en las situaciones de contacto con los europeos.

Las culturas indígenas de Norteamérica dan el mentís a la imagen de sociedades "frías", ahistóricas y repetitivas que concibiera Claude Lévi-Strauss (1966 [1962]: 233). Aunque las definiciones de Lévi-Strauss no nos permiten calificarlas como "cálidas", las sociedades indígenas de Norteamérica sufrieron un rápido deshielo al final de su época prehistórica, y el hielo continuó derritiéndose como respuesta al contacto con Europa. La milagrosa supervivencia de distintas culturas nativas norteamericanas hasta el presente, a pesar de políticas deliberadas (o contingentes) de genocidio, sociocidio y aculturación forzada, se atribuye habitualmente al racismo, la marginación, la negligencia, y las olas periódicas de proteccionismo benévolo motivadas por catástrofes nacionales o internacionales. Sin embargo, el público en general desconoce la solidez interna de las sociedades indígenas, la que se expresa a través del idioma del parentesco, los sentimientos comunitarios duraderos, la efectividad política y legal de los líderes nativos y las ventajas de adaptación que existen en lo que percibimos, de manera derrogativa, como faccionalismo. Sin embargo, el factor que podría resultar decisivo para la supervivencia indígena es el elevado desarrollo de su conciencia histórica: una noción ininterrumpida de su identidad como pueblos particulares que derivan cierto poder a través de la preservación de su singularidad. Desde esta perspectiva, la historia no es lo que sucede entre los indígenas, sino una potente fuerza que ellos utilizan, recrean y manipulan como mecanismo de supervivencia.

La importancia del individuo en la formulación de la historia indígena es un problema sustancial, pues debemos tener cuidado en distinguir la ideología del individualismo de una noción psicológica de la individualidad o del ser. ${ }^{5}$ En realidad, aunque la ética de muchas sociedades nativas reduce el énfasis en el individuo, favoreciendo los valores colectivos, ésta también presenta un respeto profundo por el individuo y por la privacía personal. La historia indígena revela un cociente razonable de líderes, miembros de elites o individuos talentosos que emergen durante períodos de crisis, y las biografías y autobiografías de estos personajes se han incrementado de manera exponencial en las últimas décadas. ${ }^{6}$ Las tradiciones orales indígenas también subrayan las gestas milagrosas de un grupo variado de héroes culturales que modifican al mundo y al género humano al momento de incrementar su propio desarrollo individual y acercarse a la plenitud del ser. No obstante, el análisis del papel del individuo en la historia indígena aún requiere de un estudio etnopsicológico más completo y sofisticado de las teorías culturales del ser y del individuo. Esta área de investigación experimenta ahora un período de bonanza, pero se encuentra aún en su infancia.

La resistencia que los historiógrafos franceses opusieran a la historia dedicada al evento parece haber sido mermada por la creciente ola de interés en la narración histórica, y dicha ola ya acaricia ambos extremos del Atlántico. La noción de que la historia debe relatar una historia no es particularmente novedosa, puesto que la calidad de la investigación histórica ha sido evaluada tomando como base esencial la pericia narrativa del historiador. Sin embargo, cuando los historiadores iniciaron su búsqueda de nuevos conceptos y metodologías para reforzar el rigor y el interés teórico de su disciplina en el bazar ideológico de la psicología, la antropología, la sociología y la economía, el valor de mercado de la historia narrativa tradicional se desplomó (Stone, 1987): este

\footnotetext{
${ }^{5}$ Véase el recorrido por los diversos significados de este ambiguo concepto en Lukes (1973).

${ }^{6}$ Dos estudios críticos recientes presentan una reseña apropiada de las narrativas personales escritas por indígenas norteamericanos: Para los que nos sucedan [For Those Who Come After, 1985], de Arnold Krupat, y La autobiografia indígena norteamericana [American Indian Autobiography, 1988], de H. David Brumble III. Ser y devenir indio [Being and Becoming Indian, 1989], de James A. Clifton, es una útil contribución al estudio biográfico de personajes marginales en las fronteras coloniales norteamericanas.
} 
tipo de historia era frecuentemente presentada con la despectiva calificación de "meramente narrativa". El resurgimiento de la narrativa ha sido generado por la confluencia de varias corrientes intelectuales: los estudios hermenéuticos europeos, la semiótica, el análisis de discurso, la crítica literaria, y los estudios del folklore, entre otras tendencias que percibían a la narrativa como a un medio fundamental de comunicación, como a un instrumento para el procesamiento y la recuperación de datos.

Los seres humanos generan y utilizan formas narrativas tanto en la comunicación intrapersonal como en la interpersonal. Las imágenes sensoriales pasajeras de los sueños pueden ser transformadas en textos de referencia para uso personal, o para su divulgación general; asimismo, la narrativa puede ser empleada para despertar emociones, o para facilitar la recuperación de ciertos datos en el discurso interpersonal. Si bien la narrativa se compone de una serie conexa de eventos, la construcción narrativa no requiere que dichos eventos sean ordenados en una secuencia cronológica unidireccional. Los eventos pueden ser obtenidos de niveles diversos, seguir direcciones divergentes, ordenarse de acuerdo con escalas cronológicas disímiles o entrecruzarse; los eventos no generan la narrativa, sino que son seleccionados para formar líneas narrativas, marcos de acción o tramas inteligibles. El proceso de selección juega un papel crucial, ya que los eventos pueden formar un grupo muy restringido o ser infinitos; el criterio de selección depende de la manera en que los eventos encajan dentro de una trama. Es por ello que la historia no puede ser considerada como universal, singular, y absoluta, o escribirse con una $H$ mayúscula: la historia narrativa se compone siempre de "historias de x" escritas desde una perspectiva particular. De esta manera, el historiador no tiene que ser el esclavo de los llamados "hechos", y se transforma en un autor de resúmenes que construye textos a partir de ciertos "hechos" y eventos. El historiador hace a la historia, y la historia no existe como una serie de narrativas prefabricadas que aguardan su descubrimiento.

Las necesidades propias de la teoría narrativa de la etnohistoria devienen aún más complejas debido a los modos discursivos disímiles y a la existencia de formas no escritas de documentación, de concepciones ontológicas diversas, y de marcos de referencia biculturales y multiculturales dentro de los cuales operan la mayoría de los etnohistoriadores. La tarea de construir etnohistorias es formidable y las posibles recompensas son enormes.

Hasta ahora, al dirimir los significados positivos y el uso de los eventos en la historiografía, he eludido el tema original de los eventos nulos. Por lo tanto, voy ahora a considerar los eventos nulos de manera esquemática, proponiendo algunos ejemplos sugerentes relacionados con la etnohistoria. A un nivel muy general, se debe tomar con seriedad la posibilidad — defendida por los annalistes- de que la mayor parte de la historia no se componga de eventos. Si bien los "eventos" generados por una cierta trama pueden ser construidos para fines narrativos, o para "contar un cuento", alrededor de estos eventos "reales" o fabricados se encuentra un residuo de datos culturales que tienen un interés crítico para los historiadores y los etnohistoriadores: valores, significados, símbolos, cosmologías, principios de estructuración social, y otras variables culturales sin las cuales ningún evento, real o imaginario, puede ser interpretado de forma adecuada.

Me vi forzado a dejar el ocio de la teoría social y a confrontar la realidad y el significado pragmático de la historia no eventual al presentar mi testimonio en el congreso legislativo de Estados Unidos sobre las diligencias del gobierno federal para el reconocimiento legal de los grupos indígenas norteamericanos. Cualquier grupo que solicite dicho reconocimiento debe comprobar, principalmente mediante textos documentales, que desciende de tribus nativas históricamente reconocidas como tales, que ha preservado su identidad indígena a través de los años, y que "ha mantenido influencia política tribal u otro tipo de autoridad sobre sus miembros como entidad autónoma a través de la historia hasta el presente". La tarea de obtener información documental que cumpla con estos requisitos es sumamente dificultosa, y los datos mínimos disponibles son frecuentemente difíciles de interpretar: muchos de estos grupos no fueron inscritos en ninguna fuente documental, y por lo tanto, no tienen historia para efectos de reconocimiento legal.

Una posible motivación del silencio documental sobre la existencia de dichos grupos es la adopción deliberada de la invisibilidad como una estrategia defensiva para 
eludir la posibilidad de ser discriminados, perseguidos, conscriptos en el ejército, y para evitar cualquier amenaza a su autonomía. Es posible que estos grupos hayan evadido los censos, se hayan distanciado de autoridades federales, estatales o locales, se hayan negado a enviar a sus hijos a escuelas establecidas, o que hayan evitado participar en eventos que pudieran atraer una cobertura periodística. Por lo tanto, la carencia de una historia corroborada por parte de estos grupos introduce preguntas fundamentales sobre el poder de la historia: ¿Quién la determina? ¿Quién establece sus criterios? ¿Quién la posee, en el sentido literal de la palabra?

Otro tipo de evento nulo concierne las diferencias en el reconocimiento de lo que se considera como un evento;

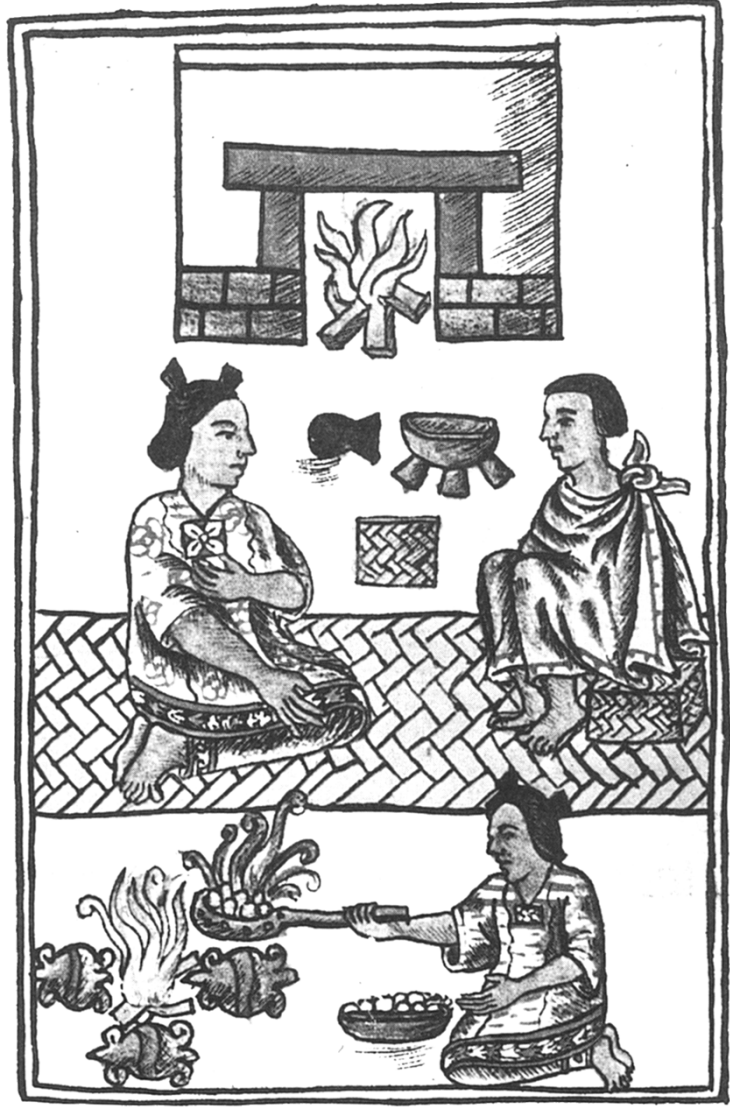

Rituales domésticos; Códice Florentino éste es un problema recurrente para los etnohistoriadores, que normalmente investigan situaciones biculturales o multiculturales. Para reciclar uno de mis ejemplos favoritos, podríamos preguntarnos si la guerra de independencia norteamericana fue un evento real para los indios norteamericanos, o un intervalo no definido en una serie de conflictos que habían iniciado mucho antes de 1776, y que continuaron después de la rendición británica en Yorktown. Cabe preguntarse si este conflicto fue para los indígenas simplemente la sustitución paternalista de George Washington I en lugar de George III de Inglaterra.

Las diferencias en la percepción de un evento se relacionan a la valorización variable del mismo, o a lo que Daniel Boorstin (1962) llamara "pseudoevento". Esencialmente, en este caso existe un consenso de que un evento tuvo lugar, de que algo sucedió, pero hay desacuerdos en cuanto al significado y consecuencias de dicho evento y la investigación etnohistórica de los tratados de paz ejemplifica esta diferencia evaluativa. Para los indios, firmar un tratado era un proceso altamente ritualizado, pues iniciaba con el intercambio de dones, para luego continuar con la alternancia de situaciones joviales y solemnes. Al final de las negociaciones, el tratado asumía las características de un hecho sagrado y eterno que se esperaba resultaría en una continua reciprocidad y en un respeto mutuo permanente; en términos maussianos, el tratado constituía un hecho social total. Sin embargo, para los blancos, la firma de un tratado era un acto instrumental y secular que había de finalizarse con celeridad; las provisiones del mismo no eran consideradas como un compromiso permanente, y podían estar sujetas a modificaciones continuas e incluso a violaciones.

Otro tipo de evento nulo podría ser llamado "evento imaginario": un incidente que nunca ocurrió, pero que podría haber ocurrido, o que debía haber ocurrido, de acuerdo con cierta lógica étnica. Se podría aplicar a este caso la noción de eventos nulos derivada de la física teórica: los eventos posibles que no han ocurrido, las posibilidades suplementarias, y las proposiciones hipotéticas pueden adquirir cierto significado para el análisis e interpretación de la historia; la adivinación y la profecía se componen de eventos imaginarios. Podríamos aducir el ejemplo concreto del sitio de Detroit por parte del 
ejército del general Pontiac — un incidente que puede ser interpretado, de manera alterna, como la conspiración de Pontiac. Probablemente Pontiac tuvo la oportunidad de anticipar la toma de Detroit y la subsecuente retirada de las fuerzas británicas a la cordillera este de las montañas de Allegheny. Greg Dowd (1988) ha argumentado de manera brillante que tanto Pontiac como los ingleses anticiparon el posible retorno de las fuerzas francesas, y que este factor debería de figurar con prominencia en cualquier interpretación de este evento bélico.

Otro tipo de evento imaginario es lo que he llamado en otras publicaciones el evento epítome (Fogelson, 1984: 260; 1985: 84). Los eventos epítome se com- sintetizan y dramatizan ciertos procesos históricos de larga duración. Estos eventos son ficticios, pero poseen tal fuerza argumentativa y características tan convincentes que se dispersan rápidamente en un grupo social, adquiriendo una realidad etnohistórica propia. El caso típico es la narrativa cherokee sobre el Aní-kutáni. En resumen, el Aní-kutáni era un sacerdocio que abusaba de sus privilegios al tomarse ciertas libertades sexuales con las mujeres cherokee. Cierto guerrero escandalizado inició una revuelta, que resultó en la masacre de algunos miembros del Aní-kutáni y en el abrupto fin de su gobierno teocrático. Es probable que tales eventos no hayan ocurrido jamás, pero se puede interpretar esta narrativa -que proviene de varias fuentes independientes - como un resumen de cambios de larga duración y del eventual colapso de las instituciones religiosas formales de los cherokee.
Otro tipo de evento nulo puede ser designado como "evento latente". Fernand Braudel, el proponente principal de la historia sin eventos, afirma que "lo no eventual se refiere a los eventos que aún no han sido reconocidos como tales: la historia del suelo, de las actitudes mentales, de la locura, de la lucha por la supervivencia a través de las edades. Lo que se puede definir como no eventual es entonces la historicidad que aún no hemos llegado a reconocer" (citado en Ricoeur, 1980: 56). Por lo tanto, parece ser que la longue durée de Braudel puede contener eventos, si se producen las narrativas adecuadas, si se hacen las preguntas indicadas para descubrir estos eventos inéditos.

Finalmente, otro tipo de evento nulo es aquel que ha tenido lugar y puede ser corroborado, pero que es tan traumático que debe ser negado. A través de mi trabajo de campo y mis investigaciones etnohistóricas sobre los cherokee, he encontrado un número sorprendentemente reducido de narrativas cherokee sobre los dolorosos incidentes que acompañaron el éxodo forzado de este grupo étnico. ${ }^{7}$ Este silencio contrasta con la abundante documentación procedente de los diarios de los soldados norteamericanos que supervisaron este viaje de 1600 kilómetros, de las fuentes históricas que contienen las vívidas impresiones de los blancos que presenciaron el pasaje de emigrantes cherokee a través de sus pueblos, y de la cobertura periodística por parte de algunos diarios norteamericanos. Sin embargo, no existe prácticamente ningún
Mujer mixe de Mogoñé; Miguel Covarrubias, 1947
${ }^{7}$ Entre 1838 y 1839 , luego de simular un tratado de paz, el gobierno norteamericano obligó a la mayoría de los cherokee — que vivían entonces en los territorios de Tennessee, North Carolina, y Georgia - a emprender una marcha forzada hacia Oklahoma en pleno invierno. 
testimonio cherokee producido en este período, y sólo existen algunas remembranzas posteriores al éxodo cherokee y tradiciones orales muy aisladas sobre este triste evento. ${ }^{8}$ Podría argumentarse que la remoción forzada de los cherokee constituyó una experiencia tan degradante, increíble y brutalmente real que asumió el carácter de irreal dentro de la conciencia cherokee.

En el presente, no cabe ninguna duda de que las epidemias fueron eventos decisivos en la historia colonial de los indios de Norteamérica. Sin embargo, como he observado con anterioridad, existe un número muy reducido de descripciones de estas epidemias relatadas por indígenas, a pesar del enorme impacto de dichos eventos y de sus consecuencias ulteriores. Como etnohistoriadores debemos formular nuevas preguntas y ensayar nuevas tramas narrativas para intentar una explicación del silencio indígena o la amnesia total en torno a estos eventos aterradores.

El intento de clasificar los eventos nulos es una tarea fácil, pero es mucho más difícil ir más allá de la tipología y tratar de mostrar las posibilidades analíticas que emergen de nuestra confrontación de dichos eventos. Intentaré sugerir tales posibilidades mediante algunos breves comentarios sobre un tema que ha atraído la atención de historiadores, etnólogos y etnohistoriadores durante casi todo un siglo: la Danza de Fantasmas [Ghost Dance]. Las relaciones anteriores sobre este evento, que provenían principalmente de fuentes no indígenas, han sido complementadas en el presente a través de la exploración sistemática de testimonios indígenas y de significados culturales no explícitos.

La narrativa etnohistórica de Raymond DeMallie de la Danza de Fantasmas lakota, y sus esfuerzos continuos por hacer accesibles las fuentes primarias indígenas constituyen un ejemplo muy laudable. DeMallie nos presenta ciertas concepciones etnoecológicas y metafísicas de los lakota: la desaparición de los búfalos constituía un retorno migratorio a su punto de origen bajo la tierra, y se esperaba que, mediante rituales adecuados, se podría dar

\footnotetext{
${ }^{8}$ Por ejemplo, en el número especial del Journal of Cherokee Studies (1978), donde se publicaron fuentes primarias sobre el éxodo cherokee, sólo tres de las trece narrativas incluidas provienen de cherokees.
}

marcha atrás a esta migración. El inframundo era también el punto de origen de las almas humanas, aunque su destino ulterior era el mundo "de arriba"; por lo tanto, la reunión de los espíritus de los muertos con sus parientes vivos constituía una posibilidad metafísica dentro del sistema de creencias de los lakota. De estas observaciones se obtiene la conclusión de que el paso del tiempo podía seguir una trayectoria circular en vez de una línea recta, y que ciertos eventos podrían ser considerados como reversibles, en vez de ser irreversibles. La reciente obra de Russell Thornton (1986) sobre la Danza de Fantasmas toma en consideración la historia demográfica que precedió este fenómeno, y trata de interpretar su contexto. Otros expertos más competentes podrán cuestionar los cálculos demográficos, los supuestos, y lo plausible de las interpretaciones presentadas por Thornton, pero me parece que Thornton ha planteado preguntas fundamentales.

Lo que parece que hemos descuidado en nuestro intento por interpretar la Danza de Fantasmas son las nociones indígenas sobre fantasmas, espíritus, muerte, y escatología, sobre las diversas entidades vivientes que frecuentemente designamos de manera simplista como "fantasmas", y sobre el significado de las prácticas funerarias como episodios necesarios en el pasaje de espíritus de un mundo al otro. De acuerdo con mi comprensión general de las creencias espirituales de los indios norteamericanos, la muerte era concebida no como un evento, sino más bien como un proceso, y las prácticas funerarias demarcaban y facilitaban tal pasaje. Una de las consecuencias de la mortandad masiva causada por guerras y epidemias habría sido la imposibilidad pragmática de celebrar ritos funerarios adecuados: los entierros en fosa común parecen haber reemplazado aquéllos de plataforma practicados por los lakota, así como otras formas específicas de enterramiento de otros pueblos indígenas, y los ritos posfunerarios probablemente no se practicaban o se realizaban de manera muy abreviada. Dados los principios metafísicos indígenas y los horrores paralizantes de los hechos, se podría argumentar que, para muchos indígenas, estas víctimas no habían muerto por completo o de manera definitiva. En otras palabras, podría haber ocurrido una negación de la muerte. La mortandad catastrófica podría haber sido concebida como una serie 
de eventos incompletos o parciales - o como eventos nulos- cuyo curso podría ser revertido (véase Fogelson, 1985: 80-82). No sólo se podría forzar el retorno de los búfalos a través de danzas lakotas, sino que también los muertos podrían retornar de sus viajes inconclusos al otro mundo. Dejo a aquellos que posean un mejor conocimiento de estos eventos juzgar si mis hipótesis tienen fundamento o validez como líneas innovativas de investigación.

Como punto final en este ensayo quisiera subrayar que he desarrollado algunas especulaciones sólo para sugerir las posibilidades interpretativas de los eventos nulos dentro de la narrativa etnohistórica. He presentado también ciertos argumentos con los que muchos podrán estar en desacuerdo, pero espero que tales diferencias de opinión generen discusiones útiles. El desarrollo de un campo de estudio tan importante como la etnohistoria ha sido obstaculizado por la supresión de cuestiones teóricas y la existencia de una epistemología ingenua. Si la historia no me absuelve, espero que algún día me absuelvan los etnohistoriadores.

\section{Bibliografía}

Boorstin, Daniel J.,1962, The Image: or What Happened to the American Dream, Atheneum, Nueva York.

Braudel, Fernand, 1972-1973 [1949], The Mediterranean and the Mediterranean World in the Age of Philip II, dos volúmenes, trad. de Sian Reynolds, Harper and Row, Nueva York.

_ 1972 [1958], "History of the Social Sciences. Economy and Society in Early Modern Europe", en Essays from Annales, ed. de Peter Burke, Routledge y Kegan Paul, Londres.

Brumble, H. David, III, 1988, American Indian Autobiography, University of California Press, Berkeley y Los Ângeles.

Butterfield, Herbert, 1976 [1931], The Whig Interpretation of History, AMS Press, Nueva York.

— 1981, The Origins of History, ed. de Adam Watson. Eyre Methuen, Londres.

Clifton, James A. (ed.), 1989, Being and Becoming Indian: Biographical Studies of North American Frontiers, Dorsey Press, Chicago.

DeMallie, Raymond J., 1982, "The Lakota Ghost Dance: An Ethnohistorical Account", en Pacific Historical Review, 51: 385-405.
Dowd, Gregory Evans, 1988, "Pontiac and France", ponencia presentada en el congreso anual de la American Society for Ethnohistory, Williamsburg, Virginia, Estados Unidos.

Drinnon, Richard, 1980, Facing West: The Metaphysics of Indian-Hating and Empire-Building, New American Library, Nueva York.

Fogelson, Raymond D., 1974, "On the Varieties of Indian History: Sequoyah and Traveller Bird", en Journal of Ethnic Studies, 2: 105-112.

- 1984, "Who Were the Aní-Kutáni? An Excursion into Cherokee Historical Thought", en Ethnohistory, 31: 255263.

— 1985 , Night Thoughts of Native American Social History. The Impact of Indian History on the Teaching of United States History, Occasional Papers in Curriculum, núm. 3, Centro D’Arcy McNickle Center para la Historia de los Indios de Norteamérica, Biblioteca Newberry, Chicago, pp. 67-89.

King, Duane H., y E. Raymond Evans, 1978, "The Trail of Tears: Primary Documents of the Cherokee Removal", en Journal of Cherokee Studies, 3 (3): 130-187.

Krupat, Arnold, 1985, For Those Who Come After: A Study of Native American Autobiography, University of California Press, Berkeley y Los Ângeles.

Lévi-Strauss, Claude, 1966 [1962], The Savage Mind, University of Chicago Press, Chicago.

Lukes, Steven, 1973, Individualism, Harper Torchbooks, Nueva York.

Martin, R. M., 1978, Events, Reference and Logical Form, Catholic University of America Press, Washington.

Novick, Peter, 1988, That Noble Dream: The "Objectivity Question" and the American Historical Profession, Cambridge University Press, Cambridge.

Ricoeur, Paul, 1980, The Contribution of French Historiography to the Theory of History, conferencia magistral Zaharoff, Oxford University Press, Nueva York.

Sahlins, Marshall, 1981, Historical Metaphors and Mythical Realities: Structure in the Early History of the Sandwich Islands Kingdom, University of Michigan Press, Ann Arbor.

_ 1985 , Islands of History, University of Chicago Press, Chicago.

Stone, Lawrence, 1987, The Past and the Present Revisited, Routledge y Kegan Paul.

Teggart, Frederick J., Londres, 1941, Theory and Process of History, University of California Press, Berkeley y Los Ángeles.

Thornton, Russell, 1941, We Shall Live Again: The 1870 and 1890 Ghost Dance Movement as Demographic Revitalization, Cambridge University Press, Cambridge.

Wallerstein, Immanuel, 1979, Fernand Braudel, International Encyclopedia of the Social Sciences, vol. 18, Biographical Supplement, ed. de David L. Sills, The Free Press, Nueva York, pp. 69-72. 